\title{
Spiritual Leadership and its Relation to Organizational Trust among Nurses at Menoufia University Hospitals
}

\author{
Eman S. Ali ${ }^{1}$, Manal M. Ibrahim ${ }^{2}$ and Gehan M. Diab ${ }^{3}$ \\ ${ }^{l}$ Clinical instructor of Nursing Administration, ${ }^{2}$ Professor of Nursing Administration, \\ ${ }^{3}$ Assistant Professor of Nursing Administration, Faculty of Nursing-Menoufia University.
}

\begin{abstract}
Background: Spiritual leadership can guide leaders to help followers to be able to meet higher order needs. Purpose: Is to explore the relationship between spiritual leadership and organizational trust among nurses. Design: A descriptive correlational design was used in this study. Setting: the study was conducted at Menoufia university hospitals all 11 ICU units, all 6 operation room, all 21deparetments and 15 out patients clinics. Subjects: included all nursing managers were available 85 at the time of the study, 400 staff nurses were selected by simple random sample to participate in the study. Data collection Instruments: spiritual leadership and organizational trust questionnaire. Results: the highest percentage of nursing managers' perception was observed between moderate and high level of spiritual leadership. The highest percent of staff nurses had low levels of organizational trust dimensions while the lowest percent of staff nurses had high levels of organizational trust dimensions. Conclusion: there was positive statistically significant correlation between nursing managers' altruistic love levels and staff nurses' organization's trust dimension. Also there was positive statistically significant correlation between nursing managers' membership levels and staff nurses' nursing managers' trust dimension and staff nurses' organizational trust dimension and the medium score of staff nurses' organizational trust levels increased with increase of nursing managers' levels of spiritual leadership medium score. Recommendations: the nursing managers should use the application of innovative styles such as spiritual leadership to improving the organizational trust among staff nurses
\end{abstract}

Key words: Nursing managers, Organizational trust, Staff nurses and Spiritual leadership.

\section{Introduction}

The health care environments are increasingly demanding environments rendering nurses a vulnerable group experiencing a high degree of stress due not only through exposure to high patient acuity but also by understaffing, limited support, and long working hours. So a growing need to the spiritual leadership is more crucial, as the result of global rapid change, to improve motivation and commitment of the employees in order to optimize organizational performance

Handayani \& Bakhris, 2017).

Spiritual leadership is one of the approaches that have been seriously 


\section{Spiritual Leadership and its Relation to Organizational Trust among Nurses at Menoufia University Hospitals}

raised in the theoretical foundations of leadership and management in the last decades of the 20th century. The Spiritual Leadership movement contains leadership serving models, staff participation and empowering them based on the philosophy of servant leadership. The spiritual leader is one who, in dealing with organizational situations, instead of interfering in affairs, shows inspiration; as a substitute of controlling, trust, instead of imposing restrictions, independence, rather than acting, imaging and modesty rather than showing off ( Pruzan , Pruzan, Miller \& Miller, 2017).

Spiritual leadership can have a positive effect on staff performance. When organizations promote hope and happiness, staff nurses are better able to deal with stressors in the work environment, further contributing to organizational performance. Spiritual leaders nourish identification and a sense of membership that supports open communication (Narcıkara \& Zehir, 2016).

Health professionals team members want a work culture that characterized by trust and respect where they have the capacity and skills to make contributions to achieve the organizational goals and objectives.
Interactions among health care workers influenced by trust that enables the staff to surface their ideas and feelings, use each other as resources, and learn organizational trust is one of the important components in the organizational success and have a great advantage for organizations. It is defined as a psychological state by providing a feedback on how employees perceive the problems in the situations in which the organization is endangered (El Banan \& Elewa, 2019). Trust in organization is defined as the confident, positive expectations of employees about the intention and behavior of multiple constituencies of an organization regarding the organization's conduct, motives, and intentions in an organizational setting (Lumineau, 2017).

In organization that has a strong spiritual leadership, leader's influence is extremely important in order to bring the members in the process of approaching the goals. Spiritual leadership is essentially a personspecific characteristic in influencing the members of the organization in order to achieve organizational goals. Effective leaders will provide encouragement and direct the organization and its member to work carefully in term to achieve the desired goals. Effect of the leader who 


\section{Spiritual Leadership and its Relation to Organizational Trust among Nurses at Menoufia University Hospitals}

directs the organization in achieving its goal will provide assurance to members of the organization for relying and acting in accordance with the given direction. Trust itself is defined as a willingness to rely on an authority that is based on positive expectations for the action and intention of the authorities. Strong trust of the members to organizations is affected by the leader's ability to influence its members (Setiawan, Putrawan, Murni \& Ghozali, 2016).

\section{Significance of the Study}

In recent years, more attention has been paid to the spiritual characteristics of leadership, and how leaders establish mutual and appropriate spiritual relationships with staff. Job makes life meaningful apart from providing an income; thus, work without the soul is disturbing and may lack in the true sense of meaning (Ebrahimi, Kazemi \& Salajegheh, 2016).

The previous studies have focused on the impact of spiritual leadership on essential individual and organizational outcomes in a specific country (Chen \& Yang, 2012; Fry et al., 2005), to date, a little studies have investigated the relationship between spiritual leadership and organizational trust.
This study might provide insight into future research on spiritual leadership and organizational trust among staff nurses. The potential contribution of this study might bring a new insight to the study of spiritual leadership and its relation to organizational trust among nurses. The hospitals that experience low trust level might consider spiritual leadership development to change their organizational culture so, the present study conducted to explore the influence of spiritual leadership on organizational trust among nurses.

\section{Purpose of the study}

To explore the relationship between spiritual leadership and organizational trust among nurses at Menoufia University hospitals.

\section{Research Questions}

1) What is the level of spiritual leadership as perceived by nurse mangers?

2) What is the level of organizational trust among nurses?

3) Is there a relation between spiritual leadership and organizational trust among nurses?

\section{Methods}

Study Design

Descriptive correlational design was conducted.

Study Sample: 


\section{Spiritual Leadership and its Relation to Organizational Trust among Nurses at Menoufia University Hospitals}

The subjects of the study consisted of two different study groups; the first group include all nursing managers (85) who were available at the time of the study and who selected by convenience sample. The second group included 400 staff nurses selected by random sample and the sample size was determined by using Emmel formula $2013(\mathrm{n}=\mathrm{N} / 1+$ (Ne2).

\section{Study Setting:}

The study was conducted at selected units at Menoufia university hospitals at Shebin El-Kom, including the following areas: all 11 ICU units, all 6 operation room, all 21deparetments and 15 out patient's clinics.

\section{Instruments of data collection}

Two instruments were used for data collection:

\section{First instrument: spiritual leadership questionnaire :}

It was developed by Matherly, Fry and Ouimret (2006). It was adapted by the investigator to explore nursing mangers perceptions of spiritual leadership based on their point of view in the work setting. It consisted of two parts :

\section{Part one :}

Socio-demographic characteristics of nurse managers .It was include hospital name, age, gender, qualifications, position, marital status, years of experiences in nursing .

\section{Part two:}

Spiritual leadership questionnaire. It consists of 35 items grouped under 7 dimensions; vision (5 items), hope faith (5 items), altruistic love (7 items), meaning calling (4 items), membership (5 items), organizational commitment (4 items) and productivity (5 items)

\section{Scoring system:}

Subjects responses were scored on three point likert scale as follows 1- disagree 2- neutral 3-agree.The scores of the items of each dimension and the total scale were summed-up and the total divided by the corresponding number of items, giving mean scores. These scores were converted into percent scores. The level of spiritual leadership was considered low if the percent score was $(<60 \%)=(35-62)$. The level of spiritual leadership was consider moderate if the percent score was (60$75 \%)=(63-78)$ or the level of spiritual leadership was consider high if the percent score was $(>75 \%)=(79$ 105).

\section{Second instrument: Organizational} trust questionnaire :

It was developed by Omarov (2009). It was adapted by the investigator to assess the organizational trust among nurses. It consisted of two parts: 


\section{Part one :}

Socio-demographic characteristics of the staff nurses .It included hospital name, age, gender, qualifications, marital status, years of nursing experiences in the department.

\section{Part two:}

Organizational trust questionnaire consists of 23 itmes and were divided to three dimensions as followed: nursing managers' trust : (8 items), Colleagues' trust: (6 items), Organization's trust : (9 items).

\section{Scoring system :}

Subjects responses were scored on three point likert scale as follows 1- disagree 2- neutral 3-agree. The scores of the items of each dimension and the total scale were summed-up and the totals divided by the corresponding number of items, giving mean scores. These scores were converted into percent scores. The level of organizational trust was consider low if the percent score was $(<60 \%)=(23-39)$. The level of organizational trust was consider moderate if the percent score was (60$75 \%)=(40-49)$ or the level of organizational trust was consider high if the percent score was $(>75 \%)=(50$ 66).

Validity and Reliability of instruments:

Validity
A Bilingual group of five experts (three professor and two assistant professors) were selected to test the content and face validity of instruments. Three from the Nursing Administration Department faculty of nursing Menoufia University and two from psychiatric mental health nursing department faculty of nursing Menoufia University No modifications were required.

\section{Reliability}

\section{A. Spiritual leadership questionnaire.}

This instrument was tested to reliability by internal consistency coefficient alpha was (.84).

\section{B. Organizational trust} questionnaire

This instrument was tested to reliability by internal consistency coefficient alpha was (.91).

\section{Ethical considerations:}

Approval was obtained from the Ethics Committee of the Faculty of Nursing, Menoufia University. The privacy and confidentiality of data were maintained and assured by getting participants' consent to participate in the research before data collection. Anonymity of participants was granted.

\section{Pilot study:}

After reviewing the instrument by the experts, the investigator conducted the pilot study before administrating the 
final questionnaire. The purpose of pilot study was to ascertain clarity, relevance, applicability of the study instruments and to determined obstacles that may be encountered during data collection. It also helped to estimate the time needed to fill the questionnaire tools. The pilot study was carried on 40 staff nurses and 10 nurse manager which presented $(10 \%)$ of the sample size to evaluate the feasibility and clarity of the instrument. There was no change was made so this sample was included in the study.

\section{Procedure:}

An official letter was sent from the Dean of the faculty of nursing Menoufia University to the director of Menoufia University Hospital explaining the purpose and method of data collection. The investigator explained the purpose of the study to every participant. The investigator was available for help to avoid any misinterpretations of questions during data collection. An oral consent was taken from each study subject. Collection of data at Menoufia university hospital took from 24-1-2020 to 7-3-2020. The time needed to complete each instrument sheet was 1520 minutes. The appropriate time of data collection was according to type of work and work load of each department.

\section{Data Analysis:}

Data entry was done using SPSS (Version 20) quantitative data were expressed as mean and standard deviation and quantitative data were expressed frequency and percentage.

Chi Square test was used in this study to identify whether there are statistically significant differences between the responses of nurses in the sample for each item. One way ANOVA test also was used at this study for variable had more than two groups as educational level, marital status, and years of experience. As this test was used to describe phrases in term of frequency, percentage, mean and standard deviation of the variables. Spearman`s test was used for to find correlation between study variables $\mathrm{P}$ value) considered high significance at $\mathrm{P}$-value $<0.001$, significant at Pvalue $\leq 0.05$.

\section{Results:}

\section{Table (1): Percentage distribution of the study nursing managers according to} their socio-demographic characteristics (no 85). 
Spiritual Leadership and its Relation to Organizational Trust among Nurses at Menoufia University Hospitals

\begin{tabular}{|c|c|c|}
\hline & Frequency & Percent \\
\hline $\begin{array}{l}\text { Age: } \\
20-<35 \\
35-<45 \\
45+\end{array}$ & $\begin{array}{l}14 \\
46 \\
25\end{array}$ & $\begin{array}{l}16.5 \\
54.1 \\
29.4\end{array}$ \\
\hline $\begin{array}{l}\text { Gender: } \\
\text { Male } \\
\text { Female }\end{array}$ & $\begin{array}{c}2 \\
83\end{array}$ & $\begin{array}{c}2.4 \\
97.6\end{array}$ \\
\hline $\begin{array}{l}\text { Marital status: } \\
\text { Married } \\
\text { Unmarried }\end{array}$ & $\begin{array}{c}79 \\
6\end{array}$ & $\begin{array}{c}92.9 \\
7.1\end{array}$ \\
\hline $\begin{array}{l}\text { Nursing qualification: } \\
\text { Diploma } \\
\text { Bachelor }\end{array}$ & $\begin{array}{l}12 \\
73\end{array}$ & $\begin{array}{l}14.1 \\
85.9\end{array}$ \\
\hline $\begin{array}{l}\text { Job position: } \\
\text { Units supervisor } \\
\text { Head nurse } \\
\end{array}$ & $\begin{array}{c}5 \\
80\end{array}$ & $\begin{array}{c}5.9 \\
94.1\end{array}$ \\
\hline $\begin{array}{l}\text { Experience years: } \\
<5 \\
5-<10 \\
10+ \\
\end{array}$ & $\begin{array}{l}13 \\
34 \\
38\end{array}$ & $\begin{array}{l}15.3 \\
50.0 \\
44.7\end{array}$ \\
\hline
\end{tabular}

Table (1): This table showed that all most of the nursing managers were at age between 35 to 45 years $(54.1 \%)$. According to gender and marital status, the majority of nursing managers were female $(97.6 \%)$ and married $(92.9 \%)$. According to nurse qualification, the majority of nursing managers had bachelor degree in nursing (85.9\%). Regarding to job position and years of experience, the majority of nursing managers were head nurses $(94.1 \%)$ and they had more than 10 years of experience (50\%).

Table (2): Percentage distribution of the study staff nurses according to their socio-demographic characteristics $(n=400)$.

\begin{tabular}{|l|c|c|}
\hline & Frequency & Percent \% \\
\hline Age: & & 34.5 \\
$20-<35$ & 138 & 49.0 \\
$35-<45$ & 196 & 16.5 \\
$45+$ & 66 & 30.3 \\
\hline Gender: & 121 & 69.8 \\
Male & 279 & \\
Female & & 76.3 \\
\hline Marital status: & 305 & 23.8 \\
Married & 95 & 27.5 \\
Unmarried & & 45.5 \\
\hline Nursing qualification: & 110 & 27.0 \\
Nursing school diploma & 182 & \\
Nursing institute diploma & 108 & 38.0 \\
Bachelor & & 34.5 \\
\hline Experience years: & 152 & 27.5 \\
<5 & 138 & 110 \\
5-<10 & & \\
$10+$ & & \\
\hline
\end{tabular}


Table (2): This table showed that the highest percent of staff nurses were found at age between $35-<45 y e a r s$ (49.0\%). According to gender and marital status, more than two third of staff nurses were female $(69.8 \%)$ and married $(76.3 \%)$. Regarding to nursing qualification and years of experience, the majority of staff nurses had nursing institute diploma $(45.5 \%)$ and they had less than five years of experience $(38.0 \%)$.

Table (3): Distribution of nursing managers according to their level of spiritual leadership and its dimensions $($ no= $=85)$.

\begin{tabular}{|c|l|l|l|l|l|l|}
\hline \multirow{2}{*}{ Spiritual leadership } & \multicolumn{3}{l|l|l|}{ High } & \multicolumn{2}{l|}{ Moderate } & Low \\
\cline { 2 - 7 } & No. & $\%$ & No. & $\%$ & No. & $\%$ \\
\hline 1. Vision & 62 & 72.9 & 11 & 12.9 & 12 & 14.12 \\
2. Hope/faith & 51 & 60.0 & 22 & 25.9 & 12 & 14.1 \\
3. Altruistic love & 26 & 30.6 & 14 & 16.5 & 45 & 52.9 \\
4. Meaning/calling & 73 & 85.9 & 8 & 9.4 & 4 & 4.7 \\
5. Membership & 41 & 48.2 & 19 & 22.4 & 25 & 29.4 \\
6. Organizational commitment & 45 & 52.9 & 6 & 7.1 & 34 & 40.0 \\
7. Productivity efficiency & 44 & 51.8 & 24 & 28.2 & 17 & 20.0 \\
\hline
\end{tabular}

Table (3): This table showed that the nursing managers' levels were the highest level of meaning / calling dimension $(85.9 \%)$ followed by vision dimension (72.9\%) while they had moderate level of productivity efficiency dimension (28.2\%) and they had low level of altruistic love dimension $(52.9 \%)$.

Figure (1): Total levels of spiritual leadership among nursing managers:

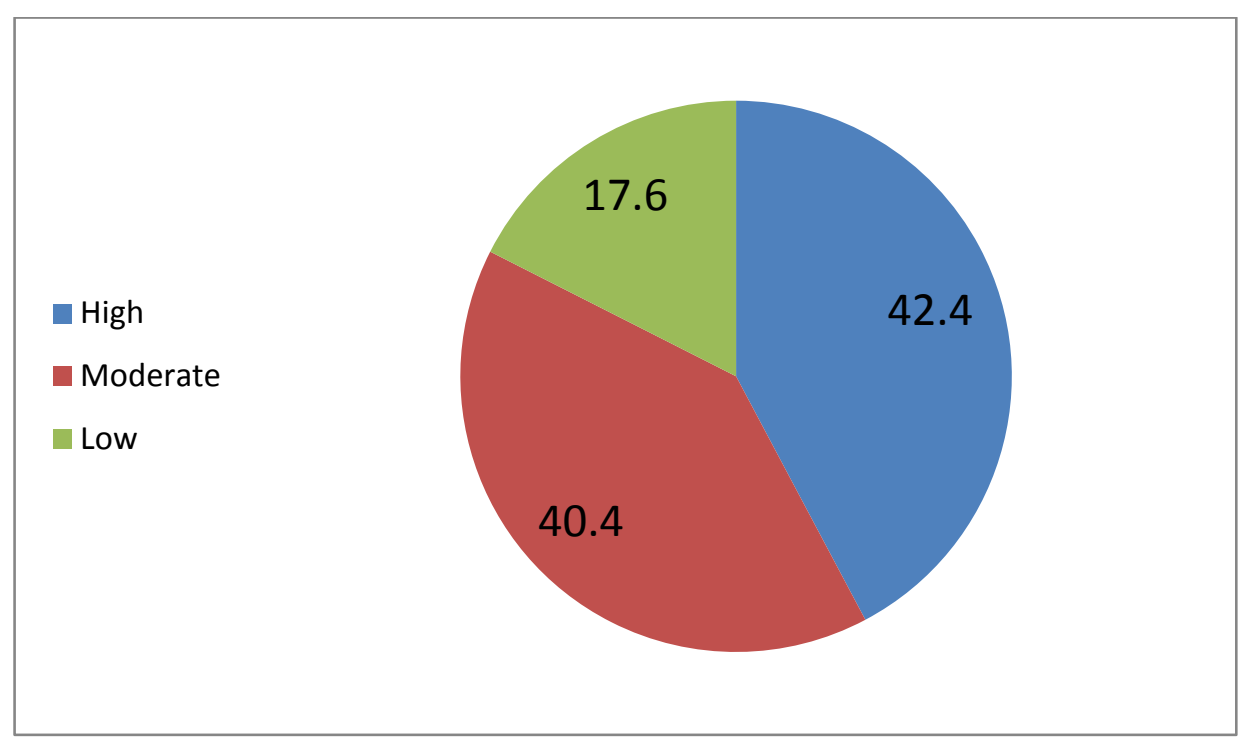


Spiritual Leadership and its Relation to Organizational Trust among Nurses at Menoufia University Hospitals

This figure shows that the highest moderate and high level of spiritual percentage of nursing managers' leadership (40.4\% and $42.4 \%$ ).

perception was observed between

Table (4): Percentage distribution of staff nurses levels of organizational trust dimensions $(n=400)$.

\begin{tabular}{|c|c|c|c|c|c|c|}
\hline \multirow{2}{*}{ Organizational trust dimensions : } & \multicolumn{2}{|c|}{ High } & \multicolumn{2}{|c|}{ Moderate } & \multicolumn{2}{|c|}{ Low } \\
\hline & No & $\%$ & No & $\%$ & No & $\%$ \\
\hline 1. Nursing managers' trust & 128 & 32.0 & 53 & 13.23 & 219 & 54.77 \\
\hline 2. Colleagues' trust & 294 & 73.5 & 29 & 7.25 & 77 & 19.25 \\
\hline 3. Organization's trust & 51 & 12.75 & 56 & 14.0 & 293 & 73.25 \\
\hline
\end{tabular}

Table (4): This table showed that the had low level of nursing managers' staff nurses' levels of organizational trust $(54.77 \%)$ and organization's trust trust dimensions were high of $(73.25 \%)$.

colleagues' trust $(73.5 \%)$ while they

Figure (2) Total levels of organizational trust among staff nurses:

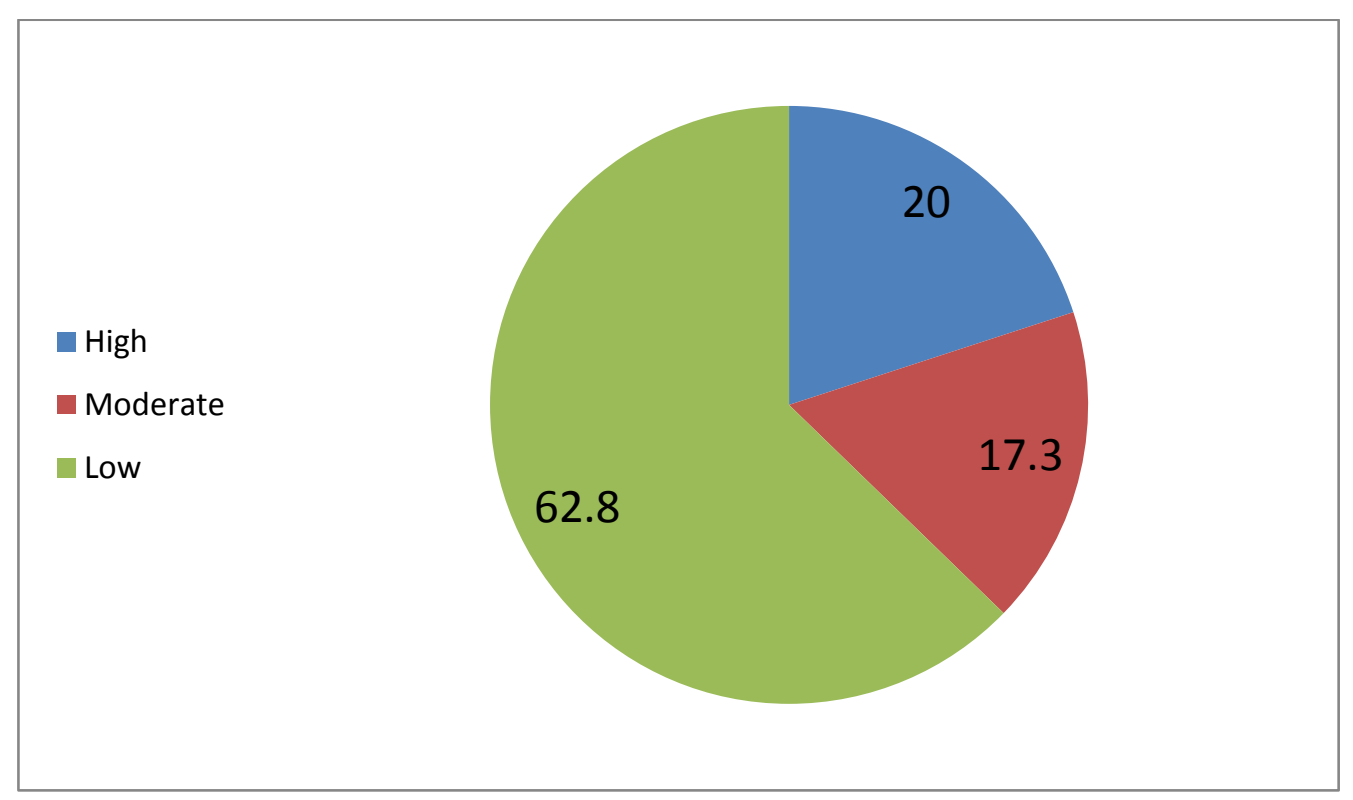

This figure showed that the highest dimensions while the lowest percent percent $(62.8 \%)$ was observed in low $(17.3 \%)$ was observed in high levels of levels of organizational trust organizational trust dimensions.

Table (5): Correlation between spiritual leadership levels and organizational trust levels as reported by the study sample. 


\begin{tabular}{|c|c|c|c|c|c|c|}
\hline \multirow{4}{*}{ Spiritual leadership domains } & \multicolumn{6}{|c|}{ Spearman's rank correlation coefficient } \\
\hline & \multicolumn{6}{|c|}{ Organizational trust domains } \\
\hline & \multicolumn{2}{|c|}{ Nursing manager } & \multicolumn{2}{|c|}{ Colleagues } & \multicolumn{2}{|c|}{ Organization } \\
\hline & $\mathrm{r}$ & p-value & $\mathrm{r}$ & p-value & $\mathrm{r}$ & p-value \\
\hline 1. Vision & -.166 & .282 & .224 & .144 & -.081 & .600 \\
\hline 2. Hope/faith & .176 & .252 & -.188 & .222 & .212 & .167 \\
\hline 3. Altruistic love & .255 & .202 & -.132 & .345 & .309 & $.041 *$ \\
\hline 4. Meaning/calling & .142 & .356 & -.067 & .665 & .070 & .652 \\
\hline 5. $\quad$ Membership & .301 & $.047 *$ & -.186 & .226 & .309 & $.041 *$ \\
\hline 6. Organizational commitment & .184 & .231 & .162 & .294 & .151 & .329 \\
\hline 7. Productivity efficiency & .108 & .487 & .282 & .064 & .096 & .534 \\
\hline
\end{tabular}

(*) Statistically significant at $\mathrm{p}<0.05$

Table (5): This table showed that there was positive statistically significant correlation between nursing managers' altruistic love levels and staff nurses' organization's trust dimension $(\mathrm{P}=$ 0.041). Also there was positive trust dimension $(\mathrm{P}=0.041)$.

\section{Figure (3): Ecological correlation between nursing managers' total spiritual}

leadership and staff nurses' organizational trust scores:

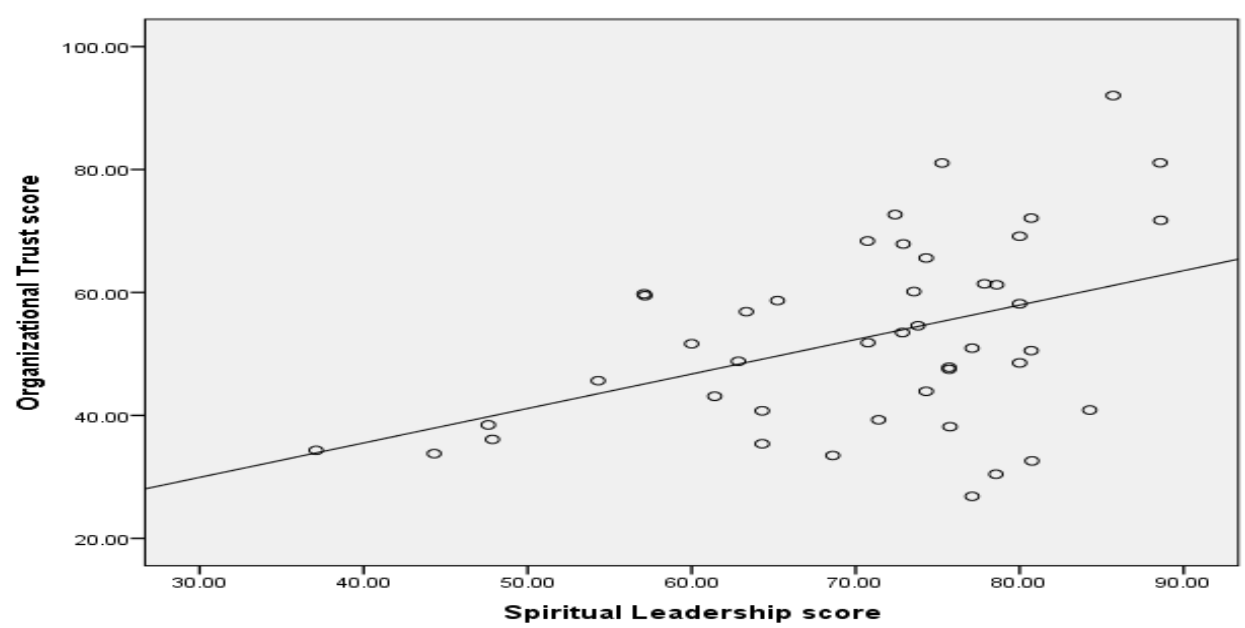

This figure display ecological with increase of nursing managers' correlation between nursing managers' levels of spiritual leadership medium spiritual leadership and staff nurses' score.

organizational trust. This figure showed that the medium score of staff nurses' organizational trust levels increased 


\section{Spiritual Leadership and its Relation to Organizational Trust among Nurses at Menoufia University Hospitals}

\section{Discussio}

Healthcare environments are answers the first question of the study increasingly demanding environments consider nurses a vulnerable group experiencing a high degree of stress due not only through exposure to high patient acuity but also by understaffing, limited support, and long working hours so healthcare organizations require strong leadership and management to achieve maximum effectiveness ,high productivity, commitment and motivation. Effective leaders are able to influence others by developing visions of the future. These leaders inspire, motivate, and empower staff toward goal attainment in the organization. In recent years, more attention has been paid to the spiritual characteristics of leadership, and how leaders establish mutual and appropriate spiritual relationships with staff (Handayani \& Bakhris, 2017).

This study was aimed to explore the relationship between spiritual leadership and organizational trust among nurses at Menoufia university hospitals.

In relation to the level regarding to spiritual leadership among nursing managers in the study setting the result revealed that the nursing manager's levels of spiritual leadership were between moderate and high. This result 


\section{Spiritual Leadership and its Relation to Organizational Trust among Nurses at Menoufia University Hospitals}

leadership among the majority of studied nurse managers, was high.

While, the study results were contradictory with Namdar et al., (2019), who reported that the nurses managers perception of spiritual leadership was low.

The present study showed that there was statistically significant correlation between spiritual leadership dimensions with each other dimensions. There was statistically significant between hope/faith and meaning/calling dimensions with vision dimension and there was highly statistical statistically significant between altruistic love and membership dimension with vision dimension. Also there was highly statistical statistically significant between membership dimensions and altruistic love dimension. This study show also there was highly statistically significant between organizational commitment dimension and altruistic love dimension and membership.

Finally the study show there was highly statistically significant between productivity efficiency dimension and meaning and calling dimension. from investigator point of view, this result may be due to nursing managers in the study sample had communication skills , more experienced and had characteristics of spiritual leader such as wisdom, Kindness, empathy, honesty, patience, courage, integrity, trust, loyalty, and humility, which these characteristics improve and increase their levels of spiritual leadership and its dimension.

The finding of the present study in the same line with the study done by Dargahi, Nasrollahzaedeh and Rahmani, (2017), who showed that there were significant correlation between spiritual leadership dimensions with each other dimensions. Also this finding goes in line with Hossein et al., (2017) and Kavousi and Nasersfahani (2015), Abdizadeh and Khiabani (2014), who found that every domain of spiritual leadership has good relationship with spiritual leadership.

In agreement of the findings of the present study .Fry et al., (2016) found that there was a strong relationship between membership and altruistic love. The current findings also confirmed by Meng, (2016) and Kaya, (2015), who found that the importance of spiritual leadership at the workplace to satisfy the individuals need of high sense of calling and membership to perform effectively. These positive feelings toward the organization positively affecting the 


\section{Spiritual Leadership and its Relation to Organizational Trust among Nurses at Menoufia University Hospitals}

productivity and it reflect a strong motive to the nurses. In the similar manner a study done Hunsaker, (2014), who reported that there was positive significant relationship between calling and productivity Potential explanation may be attributed that the presence of a spiritual leadership may have a stronger ability to influence productivity at the workplace compared to personal calling.

In the contrast with the present study Espinosa et al., (2017) , of their study of Preliminary validation of Fry's Spiritual Leadership Model in Colombian and Ecuadorian workers. Who stated there was no significant relationship between hope / faith and altruistic love with vision dimension and there was moderate relationship between meaning and calling dimension with vision dimension.

The present study result showed that the highest percent of staff nurses had low levels of organizational trust dimensions while the lowest percent of staff nurses had high levels of organizational trust dimensions, from investigator point of view, this result may be due to be due to the hierarchical structuring of health care organization and the managers' bureaucratic approach. Not allowing staff nurses to express their thoughts or their opinions when making decisions regarding the future of the organization.

This finding was supported by Basit and Duygulu, (2018), who stated that the total levels of organizational trust among nurses at hospitals in Turkey was low. Also, this was consistent with finding in the study done by Eltantawy, (2019) who study the perception of nursing staff toward justice and its relation to hospital commitment, which showed that the majority of the staff nurses had low level of organizational trust.

Also this result was congruent with Elewa and El Bana, (2019), of their study of organizational culture , organizational trust and work place bulling among staff nurses at public and private hospitals. This showed that the total organizational trust levels were low in public hospital compared with private hospital. This result was consistent with Al- Hamed , (2018) who found that trust perception in private hospitals is greater than public hospitals. And this findings in the same line with El-Sherbeny (2019), of her study of assessment organizational trust and commitment among nurses. Who found that third of staff nurses had low level and moderate level of organizational trust. 


\section{Spiritual Leadership and its Relation to Organizational Trust among Nurses at Menoufia University Hospitals}

While these findings were contrasted with Hassan , (2019), who study the relationship between organizational trust and knowledge sharing among nurses. Who found that more than three quarters of staff nurses $(78 \%)$ had high perception levels of organizational trust. And in contrast to the present study finding, the study carried out by El-Beseae,(2019) revealed that staff nurses total levels of organizational trust was moderate.

The present study showed that there was highly statistically significant correlation between organization's trust domain and nursing managers' trust domain, from the investigator point of view this result was due to the organizational rules and regulations can influence the staff members' perception about trustworthiness of the nursing managers and the nursing managers display the trust will create a high level of staff satisfaction and commitment to organization these help to improving the organizational trust and when the staff nurses trust their nursing managers they ultimately have confidence on their organization as whole. While a negative statistically significant correlation was observed between organization's trust domain and colleagues' trust domain.
From the investigator point of view this result was due to when staff nurses feel lack of management support and not accessing the information this reduce their organization trust and they become one hand to have their rights and sharing their ideas and concepts all of these improving their colleagues' trust. Also these findings were in the same line with Alajmi, (2016), who reported that there was significant relation between organizational trust dimension and nursing managers trust dimension. Also this result was congruent with Vanhala, (2016). Of the study of Organizational trust dimensions as antecedents of organizational commitment. Who showed that there was strong positive significant relation between organizational trust and manager's trust.

There was positive statistically significant correlation between nursing managers' altruistic love levels and staff nurses' organization's trust dimension, from the investigator point of view this result findings were due to the nursing managers who improving sense of altruistic love by providing proper performance feedback and improving sense of belonging of their staff members increasing their sense of commitment and loyalty to health care 


\section{Spiritual Leadership and its Relation to Organizational Trust among Nurses at Menoufia University Hospitals}

organization and improving their organizational trust, Also there was positive statistically significant correlation between nursing managers' membership levels and staff nurses' nursing managers' trust dimension and staff nurses' organizational trust dimension, from the investigator point of view this result findings were due to feel of membership within the organization improving the a high sense of loyalty and attachment to the organization and this improving the staff members organizational trust.

Study findings agree with Terzi, Gocen and Kaya,(2020), who study spiritual leaders for building trust in the school context, who revealed that there was a significant relationship between spiritual leadership dimensions and organizational trust dimensions, the lowest correlation between productivity and organizational trust dimensions while the highest correlation between altruistic love and organizational trust dimensions .Also This result supported by Arshad and Abbasi, (2014), who found that altruistic love forms trust among people, acting as a source for hope and faith in completing the work. And Hamed, Mojgan, Hatam, Khalil and Mahdi, (2015) asserted at the end of their study about nurses that creating altruistic behaviors, providing proper performance feedback, improving sense of belonging and valuing managers would improve organizational trust.

The present study showed that the medium score of staff nurses' organizational trust levels increased with increase of nursing managers' levels of spiritual leadership medium score, from the investigator point of view this result findings were due to that when the nursing managers neglect their staff member role in the organization and decrease interpersonal communication, sharing in decision making among them and use bureaucratic leadership style this decrease their sense of trust and when the healthcare organization use authority structure, lack of effective accountability cynicism, history of distrust and rigid organizational structure all these decease the staff nurses sense of loyalty and commitment to organization and decrease their sense of organizational trust.

These findings were congruent with Barekat and Sabbaghi, (2017), who found a significant and moderate relationship between overall spiritual leadership and organizational trust in 


\section{Spiritual Leadership and its Relation to Organizational Trust among Nurses at Menoufia University Hospitals}

addition, the present study result was supported by the study the result of Taboli and Abdollahzadeh, (2016), who found a significant relationship between spiritual leadership and trust in managers stated that it is obvious spiritual leadership style in management lead to mutual trust between supervisors and staff.

Terzi, Gocen and Kaya,(2020), who provided that organizational trust had significant correlations and relationship with spiritual leadership constructs ranging from low to high levels. The present study result was supported by the study the result of these findings were congruent with Esfahani and Sedaghat, (2015) also found significant correlations between some of Fry's spiritual leadership subscales and organizational trust. Also the results of the present study agree with Bahmani and Davoudi, (2019), who found that spiritual leadership had Strong correlation with staff nurses motivation, as well as organizational trust. They suggested that hospital managers increase their staffing quality of care in the hospital, taking into account their spiritual leadership, job engagement, and organizational trust.

These findings were congruent with Barekat and Sabbaghi, (2017), who reported that there was a positive and significant relationship between the variables of spiritual leadership, organizational trust and job involvement.

\section{Conclusion}

The study results lead to the conclusion that the nursing managers levels of spiritual leadership were between moderate and high ; Most staff nurses in the study setting had low levels of organizational trust. Finally, there was positive statistically significant correlation between nursing managers' altruistic love levels and staff nurses' organization's trust dimension. Also there was positive statistically significant correlation between nursing managers' membership levels and staff nurses' nursing managers' trust dimension and staff nurses' organizational trust dimension.

\section{Recommendations}

Based on the findings of this study, the following recommendations are proposed:

1. The nursing managers should recognize that spiritual leadership style as the best way for attaining the organizational goals; it can increase the chance of their success, and provide motivation for 
themselves and the ground for their staffs.

2. Holding training workshops for the nursing managers to acknowledge the philosophy of spiritual leadership determination of preemployment criteria for selection of the managers, based on having high spiritual quotient and using organizational psychologists in order to educate their experiences to mangers and staffs.

3. Workplace spirituality must be promoted in all health care organization, aiming the humanization of care and teams.

4. Nursing managers must have spiritual competences and must include the promotion of workplace spirituality in daily agenda as a foundational area in management.

5. The administration of health care organization should consider the best leaders who should facilitate workplace spirituality.

6. The nursing managers should maintain availability of resources required to help staff nurses preforming their work effectively to provide high quality of patient care

\section{References}

Abouzaid, K. (2019). Perspective of spiritual leadership among head nurses and its relation with staff nurses job empowerment, (unpublished master's thesis). Faculty of nursing, Banha University.

Al- Hamed, G., (2018). The difference of organizational trust between public and private hospital in Jordan. IJRDOJournal of Social Science and Humanities Research ISSN : 2456-2971.3(3), 48-56.

Alajmi, S. (2016). Linking psychological empowerment to job satisfaction and organizational commitment: Investigating the mediating effect of organizational trust. International Journal of Business and Management, 11(10), 120-140.

Barekat, G., \& Sabbaghi, N. (2017). Investigating the relationship between employees' spiritual leadership, organizational trust and job involvement at Ahvaz Jundishapur University of Medical Sciences, in southwest of Iran. Indo American Journal of Pharmaceutical Sciences, 4(12), 4783-4789.

Basit, G \& Duygulu, S, ( 2018). Nurses' organizational trust and intention to continue working at hospitals in turkey, Australian 
College of Nursing Ltd.

Published by Elsevier Ltd.

Bayighomog, S., \& Arasli, H. (2019).

Workplace spirituality-customer engagement Nexus: the mediated role of spiritual leadership on customer-oriented boundaryspanning behaviors. The Service Industries Journal, 39(7-8), 637661.

Chen, C., \& Yang, C. (2012). The impact of spiritual leadership on organizational citizenship behavior: A multi-sample analysis. Journal of Business Ethics, 105(1), 107-114. https://doi.org/10.1007/s10551011-0953-3

El- beseae,M. (2019).Nurses organizational trust perception and its relation with intention to stay working ,(unpublished master's thesis). Faculty of nursing, Banha University.

El- Tantawy, M. (2019). Perception of nursing staff toward justice and its relation to hospital commitment, (unpublished master's thesis). Faculty of nursing, Tanta University.

Elewa, A., \& El Banan, S. (2019). Organizational culture, organizational trust and workplace bullying among staff nurses at public and private hospitals. International Journal of Nursing Didactics, 9(4), 10-20.

El-Sherbeny,A.(2019). Assessment organizational trust and commitment among nurses, (unpublished master's thesis). Faculty of nursing, Port Said University.

Esfahani, S., \& Sedaghat, S. (2015).The relationship between spiritual leadership and vertical organizational trust. Journal of Scientific Research and Development, 2(5), 166-171.

Espinosa, J., Contreras, F., Esguerra, G,.\& Fierro, I. (2017). Validación preliminar del modelo de liderazgo espiritual de Fry en trabajadores colombianos y ecuatorianos. Acta Colombiana de Psicología, 20(1), 177-189.

Fry L, Latham JR, Clinebell SK, Krahnke K. (2016).Spiritual leadership as a model for performance excellence: a study of Baldrige award recipients . Journal of Management , Spirituality \& Religion. 14 (1) 126.

Fry L., Matherly L. (2006) spiritual leadership and organizational performance: An exploratory study, Tarleton State University. 
Available at http://www.precisionmi.com.

Fry, L. (2003). Toward a theory of spiritual leadership. The leadership quarterly, 14(6), 693727.

Fry, L., \& Egel, E. (2017). Spiritual leadership, 20 (3).

Fry, L., Vitucci, S., \& Cedillo, M. (2005). Spiritual leadership and army transformation: Theory, measurement, and establishing a baseline.

The

LeadershipQuarterly,16(5), 835862.

Hamed, S., Mojgan, D., Hatam, M., Khalil, Z., \& Mahdi, S. (2015). Relationship between spiritual leadership, teamwork and organizational trust in nurses. Quarterly Journal of Nursing Management, 4(3), 76-87.

Hassan, F. (2019). The relationship between organizational trust and knowledge sharing among nurses, (unpublished master's thesis). Faculty of nursing, Ain shams university.

Hossein D, Zeynab R, Hamideh R, (2017). Relationship between Spiritual Quotient and Transformational Leadership of Managers with Organizational Commitment of Staffs: A Case
Study in the Tehran University of Medical Sciences in Iran. Review Pub Administration Management, 5( 2).

Hunsaker, W. (2014). Relationship of Confucian values to spiritual leadership in a south Korean context. Asian Social Science, 10(12).

Hussein, G., \& Gad, R. (2019). Head Nurses' Spiritual Leadership and Staff Nurses' Autonomy: A Comparative Study.

Kaya A. (2015). The Relationship between Spiritual Leadership and Organizational Citizenship Behaviors: A Research on School Principals' Behaviors. Educational Sciences.15(3) 597606.

Lumineau, F., \& Schilke, O. (2018). Trust development across levels of analysis: An embeddedagency perspective. Journal of Trust Research, 8(2), 238-248. Matherly, L., Fry, L., \& Ouimret, R. (2006). A strategic scorecard model of performance excellence through spiritual leadership. Paper presented at the national meeting of the Academy of Management, Honolulu, Hawaii. motivasyonları üzerindeki etkileri: afyonkarahisar ili 
uygulaması. Uluslararası Sosyal

Araştırmalar Dergisi , 8(41), 920-938 .

Meng Y. (2016). Spiritual leadership at the workplace: Perspectives and theories (Review). Biomedical reports 5(4). 408425.

Narcıkara, E. (2016). Spiritüelite (Ruhsallık) ve iş ortamında anlam arayışı. Alanya Akademik Bakış, 2(1), 11-25.

Omarov, A. (2009). Organizational Trust and Work Satisfaction: An application in a private sector, Dokuz Eylül University Graduate School of Social Sciences Department of Busness, İzmir, (Unpublished MSc thesis). Rashidi1, N, Amiri, F, Hanani, S \& Rasouli, M. (2019). Evaluation of the relationship between leadership style of operating room head nurses and job satisfaction of operating room technologists . J Adv Pharm Edu Res, 9(2),179-185 .

Setiawan, B., Putrawan, I., Murni, S., \& Ghozali, I. (2016). Effect of organizational structure, leadership and trust on job performance of employee: A case study on employee at Universitas

Ternama. International Review of Management and Marketing, 6(4).

Terzi, R., Gocen, A., \& Kaya, A. (2020). Spiritual Leaders for Building Trust in the School Context. Eurasian Journal of Educational Research, 20(86), 135-156.

Vanhala, M., Heilmann, P \& Salminen, H. (2016). Organizational trust dimensions as antecedents of organizational

commitment. Knowledge and Process Management, 23(1), 4661. 